\title{
Seeking and embracing change
}

\author{
Maho Hamasaki is an associate professor at Osaka University, Japan. Maho's laboratory focuses on investigating \\ the mechanistic underpinnings of autophagy and the role of the autophagic process in disease.
}

\section{Maho Hamasaki}

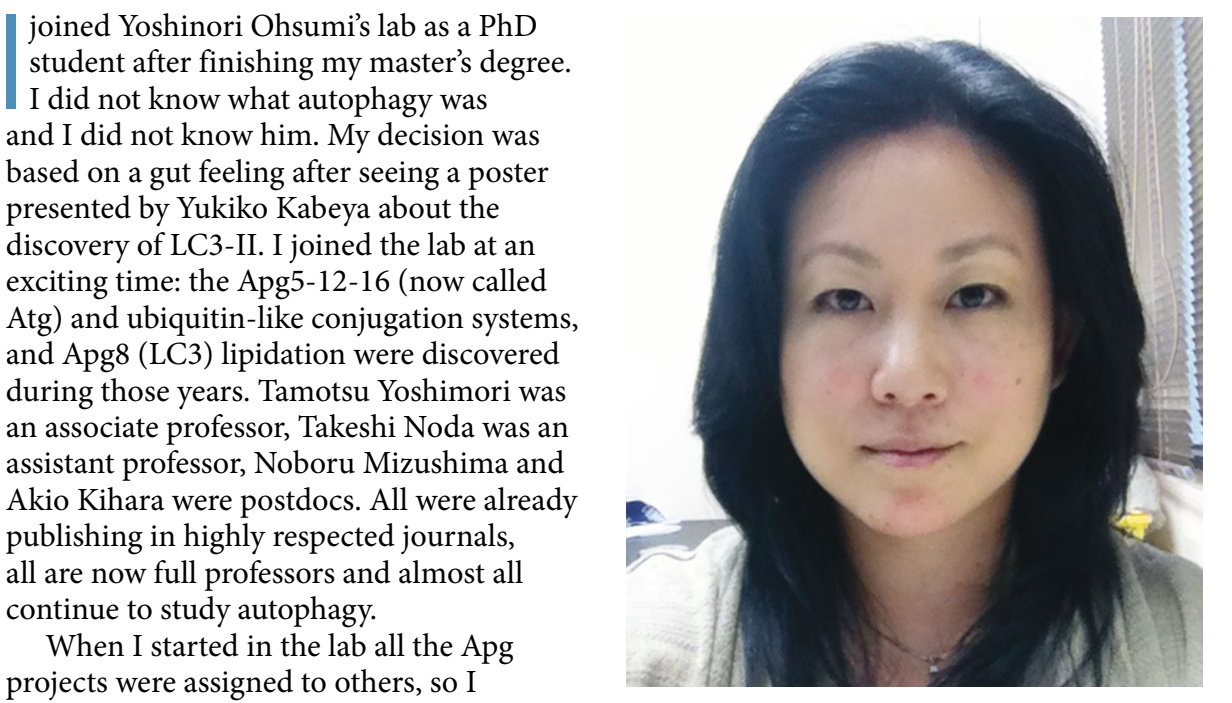

started to look at the relationship between membrane trafficking and autophagy. When autophagy is induced, a double membrane structure called the autophagosome forms by engulfing cytosol and organelles de novo. I wanted to identify the membrane source of autophagosomes and thought a type of vesicle or membrane trafficking pathway might be involved. I did rather simple experiments, labelling proteins involved in membrane trafficking with fluorescent tags and visualizing them during the autophagic process. We first found the involvement of the secretory pathway in yeast in 2001, and I wanted to get firm confirmation that endoplasmic reticulum (ER) membranes were involved. I used ER membrane proteins as markers to see if they co-localised with autophagosomes, however, we also found that part of the ER was being engulfed (a first report of 'ER-phagy'), making it difficult to distinguish whether the ER markers were inside or on the surface of autophagosome membranes by light microscopy. Immuno-labelling by electron microscopy (EM) showed that the markers were in fact present both on and inside autophagsomes, but the data were not firm enough to conclude that the ER was the membrane source.

My time in the Ohsumi lab was not always smooth - I accumulated piles of negative data - but the people and the atmosphere made it my best time in research. It was not just the excitement around autophagy research and being part of an excellent group. It was also the pleasure of having a mentor like Yoshinori Ohsumi. A very special scientist and a great person, he is often quiet but also fun, smart but not aggressive, humble but indomitable. I will always cherish my time in his lab.

During my PhD I also discovered my great love for imaging. I was captivated by the power of EM and thus joined Gareth Griffiths' group, and later Marko Kaksonens' group, at the European Molecular Biology Laboratory to study the technique as a postdoc. I have now shifted from yeast to mammalian systems, but continue to do imaging-based studies from light to electron microscopy, and this type of work excites me every day.

If the turning point of my scientific career was joining the Ohsumi lab, my life's turning point was leaving my home in Japan to move to Canada the year I turned 16. There are many Japanese scientists who were born abroad but what makes me unusual is that I moved to a completely different culture when still in school and alone. I suddenly found myself far away from my home-city of a million people, in a village called Sooke in the beautiful countryside of British Columbia. My afterschool activity became salmon fishing on a boat, while watching whales jump out of the water, and seals and sea lions waiting for a piece of salmon near the dock. At that time, high school students in Japan would mostly go between school and home, with few detours for fun. In Canada, curfew was midnight, my high school friends drove cars and pick-up trucks, and one of them even had a boat. I loved it so much that I stayed for seven years, against my parents' wishes. Of course at times it was stressful. I did not speak a word of English when I arrived, and even now I am far from being a native speaker. But my time abroad has proven invaluable in reading, writing, presenting and communicating science, and I am grateful for my parents' support and understanding. Those years not only improved my language skills but also changed my mentality, which sometimes creates difficulties for me in Japan, as I am no longer a typical Japanese person. An additional issue is that Japan has a long way to go in terms of gender equality - women still face many challenges here compared to other economically developed countries. Things are changing but not fast enough, perhaps also due to our traditional mentality and lack of diversity in the Japanese population.

After all these years back in Japan, I find myself becoming more sensitive to these struggles. When I was a PhD student, these disparities were not very apparent to me the Ohsumi lab was not a typical Japanese $\mathrm{lab}$ and as a PhD student my experience was more limited. As an independent investigator, my responsibilities mean that I constantly deal with people, conducting and discussing research, but also taking care of quiet students who might need encouragement to be heard. Sometimes I wonder if I could have done better or been more content if I had a different mentality; I hope that one day I will feel more free and happy to be who I am. But I do not wish to redo my life - I am pleased to have had all those amazing experiences, and to have embraced adventure and change.

\section{Maho Hamasaki \\ Osaka University, Osaka, Japan. \\ e-mail: hamasaki@fbs.osaka-u.ac.jp}

Published online: 28 August 2018 https://doi.org/10.1038/s41556-018-0180-6

Competing interest

The author declares no competing interests. 